\title{
Association of obesity risk SNPs in PCSK1 with insulin sensitivity and proinsulin conversion
}

\author{
Martin Heni ${ }^{\dagger 1}$, Axel Haupt ${ }^{\dagger 1}$, Silke A Schäfer ${ }^{1}$, Caroline Ketterer ${ }^{1}$, Claus Thamer ${ }^{1}$, Fausto Machicao ${ }^{1}$, Norbert Stefan', \\ Harald Staiger ${ }^{1}$, Hans-Ulrich Häring ${ }^{* 1}$ and Andreas Fritsche ${ }^{1,2}$
}

\begin{abstract}
Background: Prohormone convertase 1 is involved in maturation of peptides. Rare mutations in gene PCSK1, encoding this enzyme, cause childhood obesity and abnormal glucose homeostasis with elevated proinsulin concentrations. Common single nucleotide polymorphisms (SNPs) within this gene, rs6232 and rs6235, are associated with obesity. We studied whether these SNPs influence the prediabetic traits insulin resistance, $\beta$-cell dysfunction, or glucose intolerance.

Methods: We genotyped 1498 German subjects for SNPs rs6232 and rs6235 within PCSK1. The subjects were metabolically characterized by oral glucose tolerance test with glucose, insulin, proinsulin, and C-peptide measurements. A subgroup of 512 subjects underwent a hyperinsulinemic-euglycemic clamp.

Results: The minor allele frequencies were $25.8 \%$ for SNP rs6235 and 6.0\% for rs6232. After adjustment for sex and age, we found no association of SNPs rs6235 and rs6232 with BMI or other weight-related traits (all $p \geq 0.07$ ). Both minor alleles, adjusted for sex, age, BMI and insulin sensitivity were associated with elevated $A \cup C_{\text {proinsulin }}$ and $A \cup C_{\text {proinsulin }}$ / $A \cup C_{\text {insulin }}$ (rs6235: $p_{\text {additive model }} \leq 0.009$, effect sizes 8/8\%, rs6232: $p_{\text {dominant model }} \leq 0.01$, effect sizes 10/21\%). Insulin secretion was not affected by the variants (different secretion parameters, all $p \geq 0.08$ ). The minor allele of SNP rs6232 was additionally associated with 15\% higher OGTT-derived and 19\% higher clamp-derived insulin sensitivity $\left(p_{\text {dom }} \leq\right.$ $0.0047), 4.5 \%$ lower $\mathrm{HOMA}_{\mathbb{R}}\left(\mathrm{p}_{\mathrm{dom}}=0.02\right)$ and $3.5 \%$ lower 120 -min glucose $\left(\mathrm{p}_{\text {dom }}=0.0003\right)$ independently of BMI and proinsulin conversion. SNP rs6235 was not associated with parameters of glucose metabolism.

Conclusions: Like rare mutations in PCSK1, the more common variants tested determine glucose-stimulated proinsulin conversion, but not insulin secretion. In addition, rs6232, encoding the amino acid exchange N221D, influences insulin sensitivity and glucose homeostasis.
\end{abstract}

\section{Background}

Proteolytic cleavage is an important step in the maturation of several hormones that are derived from inactive precursors $[1,2]$. One important enzyme that catalyzes this processing is prohormone convertase 1 . This protease [3] is selectively expressed in neuronal and endocrine tissues [4] and is active within dense core secretory granules [2,3]. Among its numerous substrates [3,5] are

\footnotetext{
* Correspondence: hans-ulrich.haering@med.uni-tuebingen.de

1 Department of Internal Medicine, Division of Endocrinology, Diabetology, Angiology, Nephrology and Clinical Chemistry, Eberhard Karls University Tübingen, Member of the German Centre for Diabetes Research (DZD),

Tübingen, Germany

+ Contributed equally

Full list of author information is available at the end of the article
}

key hormones and neuropeptides for the regulation of energy metabolism, including proopiomelanocortin, proglucagon, and proinsulin [1,4,6-9].

Patients with prohormone convertase 1 deficiency (MIM: \#600955), a rare monogenic disease, suffer from childhood obesity, small intestinal absorptive dysfunction and various endocrine disturbances. They develop hypoadrenalism, hypogonadotrophic hypogonadism and abnormal glucose homeostasis with elevated proinsulin levels due to insufficient prohormone processing [9-12].

Genome-wide linkage studies identified a genomic locus on chromosome $5 \mathrm{q}$ to be associated with obesity [13-16]. Among other genes, this locus harbors PCSK1, and associations of two common single nucleotide poly- 
morphisms (SNPs) within this gene (rs6232 and rs6235, minor allele frequency $(\mathrm{MAF})=5.4 \%$ and $27.3 \%$, respectively) with obesity were reported [6].

Since prohormone convertase 1 is involved in proinsulin conversion and thereby in insulin maturation as well as in body weight regulation, the present study examined the association of the putatively obesity-related SNPs rs6232 and rs6235 in PCSK1 with the prediabetic traits insulin resistance, $\beta$-cell dysfunction, and glucose intolerance.

\section{Methods \\ Participants}

We studied 1498 non-diabetic subjects from southwestern Germany. The participants were selected from the ongoing Tübingen Family Study which currently includes $\sim 2000$ individuals with an increased risk for type 2 diabetes mellitus [17]. Selection was done based on the availability of all phenotype data used for the analyses. Especially proinsulin levels for all time points during the OGTT were not available for all subjects in the cohort. Most (68.5\%) of these subjects had a family history of diabetes, i.e., at least one second-degree relative with type 2 diabetes. Informed written consent was obtained from all participants and the local Ethics Committee approved the protocol. The OGTT revealed that $73.0 \%$ of the non-diabetic participants had normal glucose tolerance, 10.0\% had impaired fasting glycaemia, 9.6\% had impaired glucose tolerance and $7.3 \%$ had impaired fasting glycaemia and impaired glucose tolerance.

\section{Genotyping}

DNA from whole blood was isolated using a commercial DNA isolation kit (NucleoSpin, Macherey \& Nagel, Düren, Germany). Genotyping was performed using the TaqMan assay (Applied Biosystems, Forster City, CA, USA). The TaqMan genotyping reaction was amplified on a GeneAmp PCR system 7000 and fluorescence was detected on an ABI PRISM 7000 sequence detector (Applied Biosystems). The genotyping success rates were 99.0\% for rs6232 and $99.1 \%$ for rs6235. The genotypes were verified in 50 randomly selected subjects by bidirectional sequencing, and both methods resulted in 100\% identical results. Both SNPs were in Hardy-Weinberg equilibrium ( $r 66232 \mathrm{p}=0.1$ and $\mathrm{rs6235} \mathrm{p}=0.7$ ). The SNPs were incompletely linked $\left(D^{\prime}=0.887, r^{2}=0.145\right)$.

\section{OGTT}

After an overnight fast, subjects ingested a solution containing $75 \mathrm{~g}$ glucose at 08:00 hours. Venous blood samples were obtained at $0,30,60,90$ and $120 \mathrm{~min}$, and plasma glucose, insulin, C-peptide and proinsulin concentrations were determined.

\section{Hyperinsulinemic-euglycemic clamp}

Clamp-derived insulin sensitivity was determined in a subgroup of 512 subjects by a hyperinsulinemic-eugylcemic clamp with measurement of glucose and insulin. The test was performed as described earlier [18].

\section{Analytical procedures}

Plasma insulin and proinsulin were determined by commercial chemiluminescence assays for ADVIA Centaur (Siemens Medical Solutions, Fernwald, Germany). Blood glucose was measured using a bedside glucose analyzer (glucose oxidase method; Yellow Springs Instruments, Yellow Springs, OH, USA).

\section{Calculations}

The area under the curve (AUC) $\mathrm{AUC}_{\text {Ins30 }} / \mathrm{AUC}_{\mathrm{Glc} 30}$ was calculated as $\left(\mathrm{Ins}_{0}+\mathrm{Ins}_{30}\right) /\left(\mathrm{Glc}_{0}+\mathrm{Glc}_{30}\right)$. First-phase insulin was determined from the OGTT as described earlier [19] by calculating $1283+1.829 \times$ Ins $_{30}-138.7 \times$ Glc $_{30}$ $+3.772 \times$ Ins $_{0}$. AUC of glucose, insulin, C-peptide and proinsulin during the OGTT were calculated according to the trapezoid method as: $0.5 \times\left(\mathrm{c}_{0} / 2+\mathrm{c}_{30}+\mathrm{c}_{60}+\mathrm{c}_{90}+\right.$ $\left.\mathrm{c}_{120} / 2\right)$ with $\mathrm{c}=$ concentration. $\mathrm{HOMA}_{\mathrm{IR}}$ was calculated as $\left(\mathrm{Glc}_{0} \times \mathrm{Ins}_{0} \times 2\right) / 45$. Insulin sensitivity during the OGTT was estimated as proposed by Matsuda and DeFronzo [20]: ISI $=10,000 / \sqrt{ }\left(\mathrm{Glc}_{0} \cdot \mathrm{Ins}_{0} \cdot \mathrm{Glc}_{\text {mean }} \cdot \mathrm{Ins}_{\text {mean }}\right)$.

\section{Statistical analyses}

Unless otherwise stated, data are given as arithmetic means \pm SEM. Data were logarithmically transformed prior to statistical analysis. Hardy-Weinberg equilibrium was tested using $X^{2}$ test. Differences in anthropometrics and metabolic parameters between genotypes were tested using multivariate linear regression analysis. PCSK1 SNP rs6235 and SNP rs6232 were examined under both an additive (add) and a dominant inheritance model (dom). However, only the dominant inheritance model was interpreted for SNP rs6232 because of this SNP's low MAF of $6 \%$ (only 5 participants were homozygous for the minor allele). All data were adjusted for gender and age. The glucose concentrations and insulin sensitivity indices were additionally adjusted for BMI, and proinsulin concentrations and insulin secretion parameters were additionally adjusted for OGTT-derived insulin sensitivity index and BMI.

Differences with a p-value $<0.05$ were considered to indicate nominal associations. After correction for the two unlinked SNPs tested and the endpoints anthropometrics, insulin secretion, and insulin sensitivity (according to Bonferroni), results with values of $\mathrm{p}<0.0085$ were considered statistically significant. The JMP 7.0 (SAS Institute, Cary, NC, USA) statistical software package was used. 


\section{Power calculation}

Using two tailed t-test, the study was sufficiently powered (1-beta $\geq 0.8$ ) to detect an effect size of $15 \%$ for SNP rs6235 and 22\% for SNP rs6232 (dominant inheritance model, $\mathrm{p}=0.05$ ). Power calculations were performed using $\mathrm{G}^{*}$ power 3.0 software available at http://www.psycho.uni-duesseldorf.de/aap/projects/gpower/.

\section{Results}

The observed MAF for SNP rs6235 was $25.8 \%$ (reported 27.3\% [6]) and for rs6232 6.0\% (reported 5.4\% [6]).

After appropriate adjustment, both minor alleles of the PCSK1 SNPs rs6232 and rs6235 were neither associated with BMI nor with weight-related traits, like waist circumference and total body fat (all $\mathrm{p} \geq 0.07$, tables $1+2$ ). The frequency of obesity (BMI $<30$ versus BMI $\geq 30 \mathrm{~kg}$ / $\mathrm{m}^{2}$ ) in our cohort was not influenced by the risk alleles (all $\mathrm{p} \geq 0.4$ ).

None of the SNPs revealed association with fasting proinsulin concentrations (all $\mathrm{p} \geq 0.1$, tables $1+2$ ). However, upon glucose ingestion, subjects carrying the minor alleles showed an association with higher proinsulin concentrations (rs6232 nominally associated, $\mathrm{p}_{\mathrm{dom}}=0.0104$; rs6235 significantly associated with $\mathrm{AUC}_{\text {Proins }}, \mathrm{p}_{\text {add }}=$ 0.0018 ; adjusted effect sizes $10 / 8 \%$; tables $1+2$ ) and nominally lower proinsulin-to-insulin conversion $\left(\mathrm{AUC}_{\text {Proins }} /\right.$ $\mathrm{AUC}_{\text {ins }}$ ) compared to those with the major allele (rs6232, $\mathrm{p}_{\mathrm{dom}}=0.0094 ;$ rs6235, $\mathrm{p}_{\text {add }}=0.0090$; adjusted effect sizes $21 / 8 \%$; tables $1+2$, figure $1 \mathrm{~A}+1 \mathrm{D}$ ) and this finding was consistent when adjusting for insulin sensitivity or not. Both variants were not associated with differences in insulin secretion (all indices used $\mathrm{p} \geq 0.08$, tables $1+2$ ), and SNP rs6235 was furthermore neither associated with glucose nor with insulin levels during the OGTT (all $\mathrm{p} \geq$ 0.2 , figure $1 \mathrm{~B}$ and $1 \mathrm{C}$ ).

In addition to these findings, the minor allele of SNP rs6232, but not that of SNP rs6235, was significantly associated with decreased 120-min blood glucose $\left(\mathrm{p}_{\mathrm{dom}}=\right.$ 0.0003 , table 1 , figure 2) and nominally associated with decreased fasting insulin levels $\left(\mathrm{p}_{\mathrm{dom}}=0.0297\right.$, table 1 ). Insulin sensitivity derived from the OGTT was significantly increased $\left(\mathrm{p}_{\mathrm{dom}}=0.0010\right.$, adjusted effect size $15 \%$, table 1, figure 2) and insulin resistance derived from fasting state $\left(\mathrm{HOMA}_{\mathrm{IR}}\right)$ was accordingly nominally decreased in carriers of the minor allele $\left(\mathrm{p}_{\mathrm{dom}}=0.0232\right.$, table 1 and figure 2). The effect on OGTT-derived insulin sensitivity remained significant even after adjustment for gender, age, $\mathrm{BMI}, \mathrm{AUC}_{\text {Proins }} / \mathrm{AUC}_{\text {Ins }}$, and first-phase insulin secretion $\left(\mathrm{p}_{\mathrm{dom}}=0.0033\right)$.

To confirm that the association with insulin sensitivity did not solely reflect altered insulin levels due to impaired prohormone processing, we analyzed insulin sensitivity measured by exogenous administration of insulin during hyperinsulinemic-euglycemic clamp. Again, SNP rs6232, but not SNP rs6235 was associated with significantly increased insulin sensitivity $\left(\mathrm{p}_{\text {dom }}=0.0047\right.$; adjusted effect size 19\%; table 1).

To analyze subjects with low risk of type 2 diabetes mellitus versus those with a high risk, we stratified for family history of diabetes. This stratification did not produce consistent results, probably due to the limited power of the subgroups.

\section{Discussion}

\section{Association of PCSK1 with weight-related traits}

In our cohort, the reported association of the common variants rs6232 and rs6235 within the PCSK1 gene with BMI and obesity could not be replicated. This is most likely explained by the limited power of our study to detect relatively small effect sizes of the SNPs on BMI and obesity. The effect sizes detectable in our study were as small as $15 \%$, and for the established obesity risk locus FTO an effect size of about $10 \%$ could be demonstrated [21].

\section{Association of PCSK1 with proinsulin levels}

In the present study, we found that the minor alleles of both candidate SNPs in the PCSK1 gene are associated with significantly higher glucose-stimulated proinsulin levels indicating reduced proinsulin conversion, while insulin secretion was unaffected. These findings were not altered by adjustment for insulin sensitivity.

Basal proinsulin levels were unaffected by the variants in PCSK1. Thus, under basal conditions the enzyme cleaves sufficient amounts of proinsulin. However, in the state of much higher secretory demands following a glucose load, proinsulin levels and proinsulin-to-insulin ratios were increased in carriers of both SNPs and this points to insufficient insulin maturation.

Both SNPs in the PCSK1 gene alter the amino acid sequence of the protein. SNP rs6232 changes asparagine to aspartic acid (N221D) in the catalytic domain and leads to a $10 \%$ reduction of activity, while SNP rs6235 substitutes serine by threonine (S690T) without any effect on the enzymatic activity [6]. Reduced enzymatic activity due to SNP rs6232 can plausibly explain this observation, though the mechanism is less clear in the case of the other SNP, rs6235. The substituted amino acid by that variation could possibly influence binding of regulators of the enzyme's activity, its localization within the $\beta$-cell, or the available number of prohormone convertase 1 molecules via altered stability. All these effects could theoretically influence prohormone conversion.

Although both PCSK1 SNPs affect proinsulin levels, they do not alter insulin secretion after glucose stimulation. Thus, the enzyme does not represent the rate-limit- 
Table 1: Associations of PCSK1 SNP rs6232 with anthropometrics, metabolic parameters, and proinsulin conversion

\begin{tabular}{|c|c|c|c|c|c|c|}
\hline SNP & & encoding N221 & & & & \\
\hline Genotype & AA & AG & GG & $\beta_{\mathrm{adj}} \pm \mathrm{SEM}$ & $p_{\text {dom }}$ & $\mathrm{p}_{\mathrm{add}}$ \\
\hline$N(f / m)$ & $1305(875 / 430)$ & $173(106 / 67)$ & $5(3 / 2)$ & - & - & - \\
\hline Age (years) & $39 \pm 0.4$ & $40 \pm 1$ & $37.6 \pm 4$ & - & - & - \\
\hline BMI $\left(\mathrm{kg} / \mathrm{m}^{2}\right)$ & $28.5 \pm 0.2$ & $28.3 \pm 0.6$ & $29.1 \pm 6.1$ & $-0.003 \pm 0.001$ & 0.8 & 1.0 \\
\hline Waist circumference (cm) & $93.4 \pm 0.5$ & $93.1 \pm 1.2$ & $82.3 \pm 3.5$ & $-0.005 \pm 0.007$ & 0.6 & 0.9 \\
\hline Total body fat (\%) & $31.0 \pm 0.3$ & $29.6 \pm 0.8$ & $30.4 \pm 7$ & $-0.017 \pm 0.013$ & 0.07 & 0.4 \\
\hline Fasting glucose (mmol/l) & $5.1 \pm 0.1$ & $5.1 \pm 0.1$ & $5.4 \pm 0.4$ & $-0.004 \pm 0.004$ & 0.3 & 0.2 \\
\hline Glucose $_{120-\min }(\mathrm{mmol} / \mathrm{l})$ & $6.3 \pm 0.1$ & $5.9 \pm 0.1$ & $6.8 \pm 1.2$ & $-0.035 \pm 0.010$ & 0.0003 & 0.0006 \\
\hline Fasting insulin (pmol/l) & $63 \pm 1$ & $56 \pm 3$ & $59.8 \pm 33$ & $-0.041 \pm 0.019$ & 0.0297 & 0.07 \\
\hline Insulin sensitivity, OGTT (AU) & $16.3 \pm 0.3$ & $18.5 \pm 0.9$ & $25.8 \pm 7$ & $0.068 \pm 0.020$ & 0.0010 & 0.0030 \\
\hline $\begin{array}{l}\text { Insulin sensitivity, clamp-derived (AU) } \\
(N=512)\end{array}$ & $\begin{array}{l}0.083 \pm 0.003 \\
\quad(\mathrm{~N}=443)\end{array}$ & $\begin{array}{c}0.098 \pm 0.007 \\
(N=68)\end{array}$ & $0.135(\mathrm{~N}=1)$ & $0.085 \pm 0.030$ & 0.0047 & - \\
\hline $\mathrm{HOMA}_{\mathbb{I R}}\left(\mathrm{mU} \times \mathrm{mmol} \times \mathrm{I}^{-2}\right)$ & $2.4 \pm 0.1$ & $2.1 \pm 0.1$ & $2.7 \pm 1.8$ & $-0.045 \pm 0.020$ & 0.0232 & 0.07 \\
\hline$A \cup C_{\operatorname{Ins} 30} / A \cup C_{G \mid c 30}\left(\times 10^{-9}\right)$ & $41.2 \pm 0.9$ & $36.8 \pm 2.0$ & $28.1 \pm 8.3$ & $-0.001 \pm 0.017$ & 1.0 & 0.6 \\
\hline First-phase insulin (pmol/l) & $1267 \pm 24$ & $1160 \pm 53$ & $1046 \pm 273$ & $0.015 \pm 0.017$ & 0.4 & 0.7 \\
\hline $\mathrm{AUC}_{\mathrm{C}-\mathrm{Pep}} / \mathrm{AUC}_{\mathrm{Glc}}\left(\times 10^{-9}\right)$ & $319 \pm 3$ & $319 \pm 8$ & $272 \pm 29$ & $0.020 \pm 0.011$ & 0.08 & 0.2 \\
\hline Proinsulin $_{0-\min }(\mathrm{pmol} / \mathrm{l})$ & $5.8 \pm 0.2$ & $5.6 \pm 0.4$ & $12.8 \pm 8.4$ & $0.053 \pm 0.038$ & 0.2 & 0.2 \\
\hline Proinsulin $_{30-\min }(\mathrm{pmol} / \mathrm{l})$ & $11.8 \pm 0.4$ & $11.9 \pm 0.7$ & $18.6 \pm 3.7$ & $0.073 \pm 0.035$ & 0.0377 & 0.0190 \\
\hline$A \cup C_{\text {Proins }}(\mathrm{pmol} / \mathrm{l})$ & $36.2 \pm 1.0$ & $37.2 \pm 2.4$ & $52.1 \pm 12.7$ & $0.074 \pm 0.030$ & 0.0141 & 0.0089 \\
\hline Fasting proinsulin/fasting insulin & $0.128 \pm 0.002$ & $0.135 \pm 0.003$ & $0.179 \pm 0.008$ & $0.040 \pm 0.039$ & 0.3 & 0.3 \\
\hline Proinsulin $_{30-\text { min }} /$ insulin $_{30-\text { min }}$ & $0.036 \pm 0.004$ & $0.035 \pm 0.002$ & $0.064 \pm 0.004$ & $0.079 \pm 0.037$ & 0.0346 & 0.0158 \\
\hline$A \cup C_{\text {Proins }} / A \cup C_{\text {Ins }}$ & $0.050 \pm 0.016$ & $0.058 \pm 0.034$ & $0.111 \pm 0.017$ & $0.079 \pm 0.030$ & 0.0094 & 0.0026 \\
\hline
\end{tabular}

Data represent unadjusted means \pm SEM. For statistical analysis, data were In-transformed and adjusted for gender and age. Glucose concentrations and insulin sensitivity indices were additionally adjusted for BMI. Proinsulin values as well as insulin secretion parameters were additionally adjusted for BMI and insulin sensitivity (OGTT). AUC - area under the curve; $\beta_{\text {adj }}$ - effect sizes from the adjusted dominant model; BMI - body mass index; $\mathrm{HOMA}_{\mathbb{R}}$ - homeostasis model assessment-estimated insulin resistance; OGTT - oral glucose tolerance test; $p_{\text {add }}$ - $p$-values from the additive inheritance model; $p_{\text {dom }}$ - $p$-values from the dominant inheritance model; SNP - single nucleotide polymorphism. $p$-values withstanding Bonferroni correction for multiple comparisons are given in bold. 
Table 2: Associations of PCSK1 SNP rs6235 with anthropometrics, metabolic parameters, and proinsulin conversion

\begin{tabular}{|c|c|c|c|c|c|c|}
\hline SNP & & 5 (encoding S6 & & & & \\
\hline Genotype & GG & GC & $\mathrm{CC}$ & $\beta_{\text {adj }} \pm S E M$ & $\mathrm{p}_{\text {dom }}$ & $\mathrm{p}_{\mathrm{add}}$ \\
\hline$N(f / m)$ & $817(537 / 280)$ & $560(377 / 183)$ & $108(72 / 36)$ & - & - & - \\
\hline Age (years) & $39 \pm 1$ & $40 \pm 1$ & $38 \pm 1$ & - & - & - \\
\hline BMI $\left(\mathrm{kg} / \mathrm{m}^{2}\right)$ & $28.2 \pm 0.3$ & $28.7 \pm 0.3$ & $29.3 \pm 0.8$ & $0.016 \pm 0.010$ & 0.2 & 0.3 \\
\hline Waist circumference (cm) & $92.9 \pm 0.6$ & $93.9 \pm 0.7$ & $94.9 \pm 2.0$ & $0.009 \pm 0.007$ & 0.2 & 0.9 \\
\hline Total body fat (\%) & $30.7 \pm 0.4$ & $31.0 \pm 0.5$ & $31.7 \pm 1.0$ & $0.014 \pm 0.014$ & 0.7 & 0.5 \\
\hline Fasting glucose (mmol/l) & $5.1 \pm 0.1$ & $5.1 \pm 0.1$ & $5.1 \pm 0.1$ & $-0.004 \pm 0.004$ & 0.2 & 0.3 \\
\hline Glucose $_{120-\min }(\mathrm{mmol} / \mathrm{l})$ & $6.2 \pm 0.1$ & $6.3 \pm 0.1$ & $6.3 \pm 0.2$ & $0.005 \pm 0.011$ & 0.7 & 0.8 \\
\hline Fasting insulin (pmol/l) & $61 \pm 2$ & $64 \pm 2$ & $63 \pm 5$ & $0.021 \pm 0.027$ & 0.8 & 0.6 \\
\hline Insulin sensitivity, OGTT (AU) & $16.8 \pm 0.4$ & $16.4 \pm 0.5$ & $16.0 \pm 0.9$ & $-0.018 \pm 0.029$ & 0.7 & 0.7 \\
\hline $\begin{array}{l}\text { Insulin sensitivity, clamp- } \\
\text { derived }(A U) \\
(N=512)\end{array}$ & $\begin{array}{l}0.088 \pm 0.003 \\
\quad(N=286)\end{array}$ & $\begin{array}{c}0.080 \pm 0.004 \\
(N=191)\end{array}$ & $\begin{array}{c}0.091 \pm 0.009 \\
(\mathrm{~N}=35)\end{array}$ & $-0.023 \pm 0.021$ & 0.3 & 0.4 \\
\hline $\mathrm{HOMA}_{\mathbb{I R}}\left(\mathrm{mU} \times \mathrm{mmol} \times \mathrm{I}^{-2}\right)$ & $2.4 \pm 0.1$ & $2.5 \pm 0.1$ & $2.5 \pm 0.2$ & $0.017 \pm 0.029$ & 0.9 & 0.6 \\
\hline$A \cup C_{\text {Ins30 }} / A \cup C_{\mathrm{Glc} 30}\left(\times 10^{-9}\right)$ & $40.4 \pm 1.0$ & $40.2 \pm 1.3$ & $46.0 \pm 3.7$ & $0.022 \pm 0.026$ & 0.9 & 0.6 \\
\hline First-phase insulin (pmol/l) & $1247 \pm 29$ & $1251 \pm 35$ & $1383 \pm 97$ & $0.014 \pm 0.024$ & 1.0 & 1.0 \\
\hline $\mathrm{AUC}_{\mathrm{C}-\mathrm{Pep}} / \mathrm{AUC}_{\mathrm{Glc}}\left(\times 10^{-9}\right)$ & $318 \pm 3.6$ & $316 \pm 4.4$ & $343 \pm 13$ & $0.017 \pm 0.014$ & 1.0 & 0.2 \\
\hline Proinsulin ${ }_{0-\min }(\mathrm{pmol} / \mathrm{l})$ & $5.6 \pm 0.2$ & $5.9 \pm 0.3$ & $7.0 \pm 0.9$ & $0.081 \pm 0.041$ & 0.1 & 0.1 \\
\hline Proinsulin $_{30-\min }(\mathrm{pmol} / \mathrm{l})$ & $11.2 \pm 0.3$ & $12.2 \pm 0.7$ & $16.5 \pm 2.6$ & $0.117 \pm 0.038$ & 0.0286 & 0.0059 \\
\hline$A \cup C_{\text {Proins }}(\mathrm{pmol} / \mathrm{l})$ & $34.2 \pm 1.0$ & $37.0 \pm 1.5$ & $49.1 \pm 6.7$ & $0.105 \pm 0.034$ & 0.0404 & 0.0018 \\
\hline $\begin{array}{l}\text { Fasting proinsulin/fasting } \\
\text { insulin }\end{array}$ & $0.126 \pm 0.004$ & $0.129 \pm 0.003$ & $0.147 \pm 0.014$ & $0.062 \pm 0.044$ & 0.2 & 0.1 \\
\hline Proinsulin $_{30-\text { min }} /$ insulin $_{30-\text { min }}$ & $0.036 \pm 0.005$ & $0.035 \pm 0.002$ & $0.047 \pm 0.011$ & $0.105 \pm 0.041$ & 0.0208 & 0.0123 \\
\hline$A \cup C_{\text {Proins }} / A \cup C_{\text {Ins }}$ & $0.048 \pm 0.001$ & $0.053 \pm 0.003$ & $0.068 \pm 0.011$ & $0.085 \pm 0.035$ & 0.0324 & 0.0090 \\
\hline
\end{tabular}

Data represent unadjusted means \pm SEM. For statistical analysis, data were In-transformed and adjusted for gender and age. Glucose concentrations and insulin sensitivity indices were additionally adjusted for BMI. Proinsulin values as well as insulin secretion parameters were additionally adjusted for BMI and insulin sensitivity (OGTT). AUC - area under the curve; $\beta_{\text {adj }}$ - effect sizes from the adjusted dominant model; BMI - body mass index; $\mathrm{HOMA}_{\mathbb{R}}$ - homeostasis model assessment-estimated insulin resistance; OGTT - oral glucose tolerance test; $p_{\text {add }}$ - $p$-values from the additive inheritance model; $p_{\text {dom }}$ - $p$-values from the dominant inheritance model; SNP - single nucleotide polymorphism. $p$-values withstanding Bonferroni correction for multiple comparisons are given in bold. 

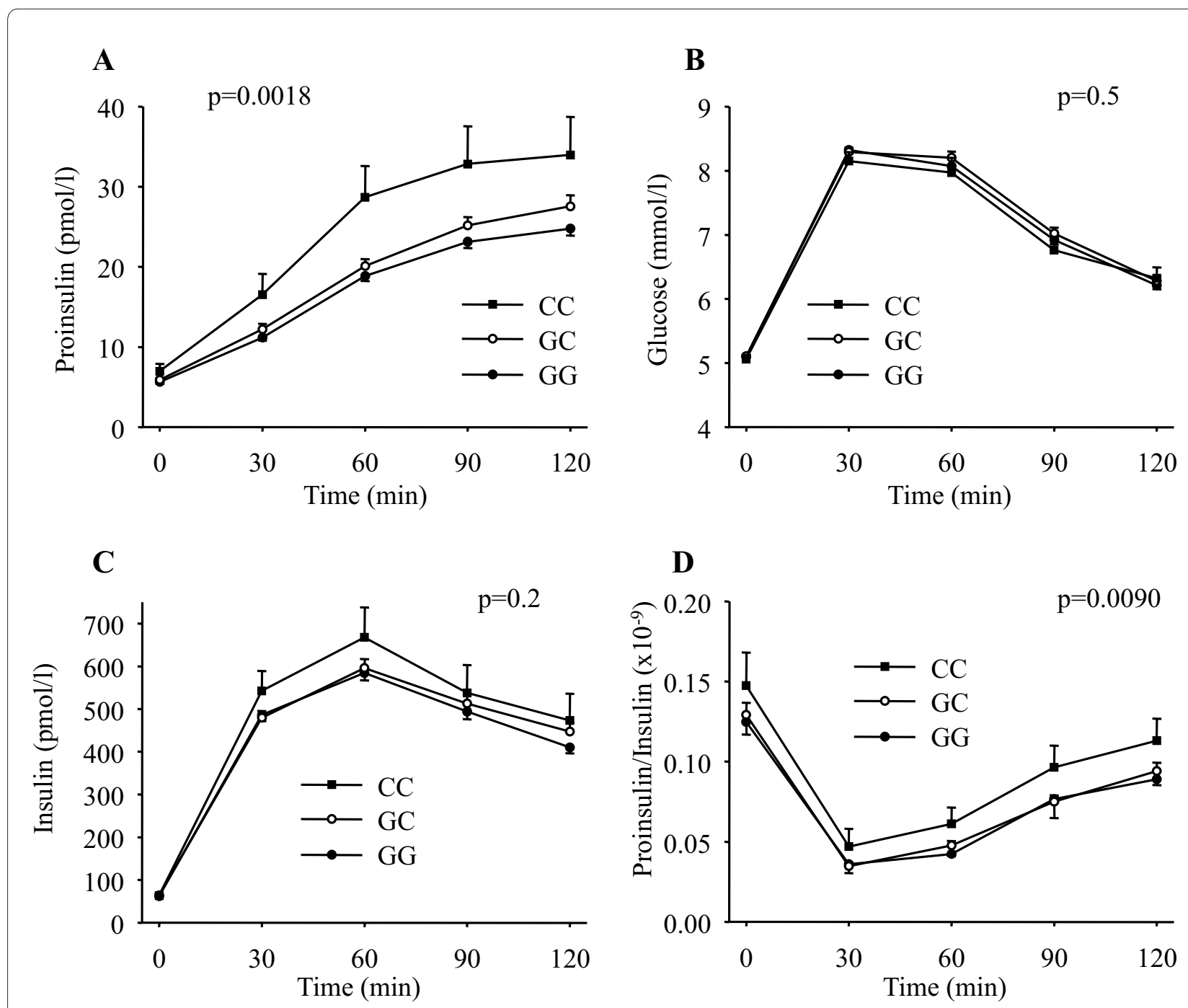

Figure 1 Plasma proinsulin (A), glucose (B), and insulin (C) concentrations as well as proinsulin-to-insulin ratio (D) during OGTT in carriers of the PCSK1 SNP rs6235. Data are given as means +/- SEM. P-values for AUC adjusted for gender, age, BMI, and insulin sensitivity are given. Black boxes: homozygous carriers of the minor allele; white circles: heterozygous carriers; black circles: homozygous carriers of the major allele.

ing step in insulin secretion which is in contrast to SNPs in diabetes risk genes which influence both proinsulin conversion and insulin secretion [22].

\section{Association of PCSK1 SNP rs6232 with insulin sensitivity}

Furthermore, the putative obesity risk allele of SNP rs6232 was unexpectedly associated with increased insulin sensitivity (fasting, OGTT-derived, and hyperinsulinemic euglycemic-clamp derived) and reduced 120-min glucose levels independently of BMI and proinsulin conversion. The similar findings with different independent measurements of insulin sensitivity as well as the inverse influence on 120-min blood glucose argue against a mere statistical type 1 error.

Since only SNP rs6232 in the PCSK1 gene, the one that decreases the enzyme's catalytic activity [6], influences insulin sensitivity, independently of BMI and proinsulin conversion, and since there is a long list of potential substrates of the prohormone convertases [3-5], it seems reasonable to speculate that the enzyme also cleaves factors that modulate insulin sensitivity (e.g. BNDF [23]).

In most cases, obesity is associated with insulin resistance. However, a proportion of overweight/obese persons display a phenotype of obesity with is metabolically benign and characterized by high insulin sensitivity [17]. Since the minor allele of SNP rs6232 was associated with higher insulin sensitivity in our study and with obesity in a large metaanalysis including more then 13,000 subjects [6], we hypothesize that this allele may promote a kind of obesity, which is more benign.

Increased proinsulin levels are reported to be a marker of insulin resistance [24]. Interestingly, for carriers of 


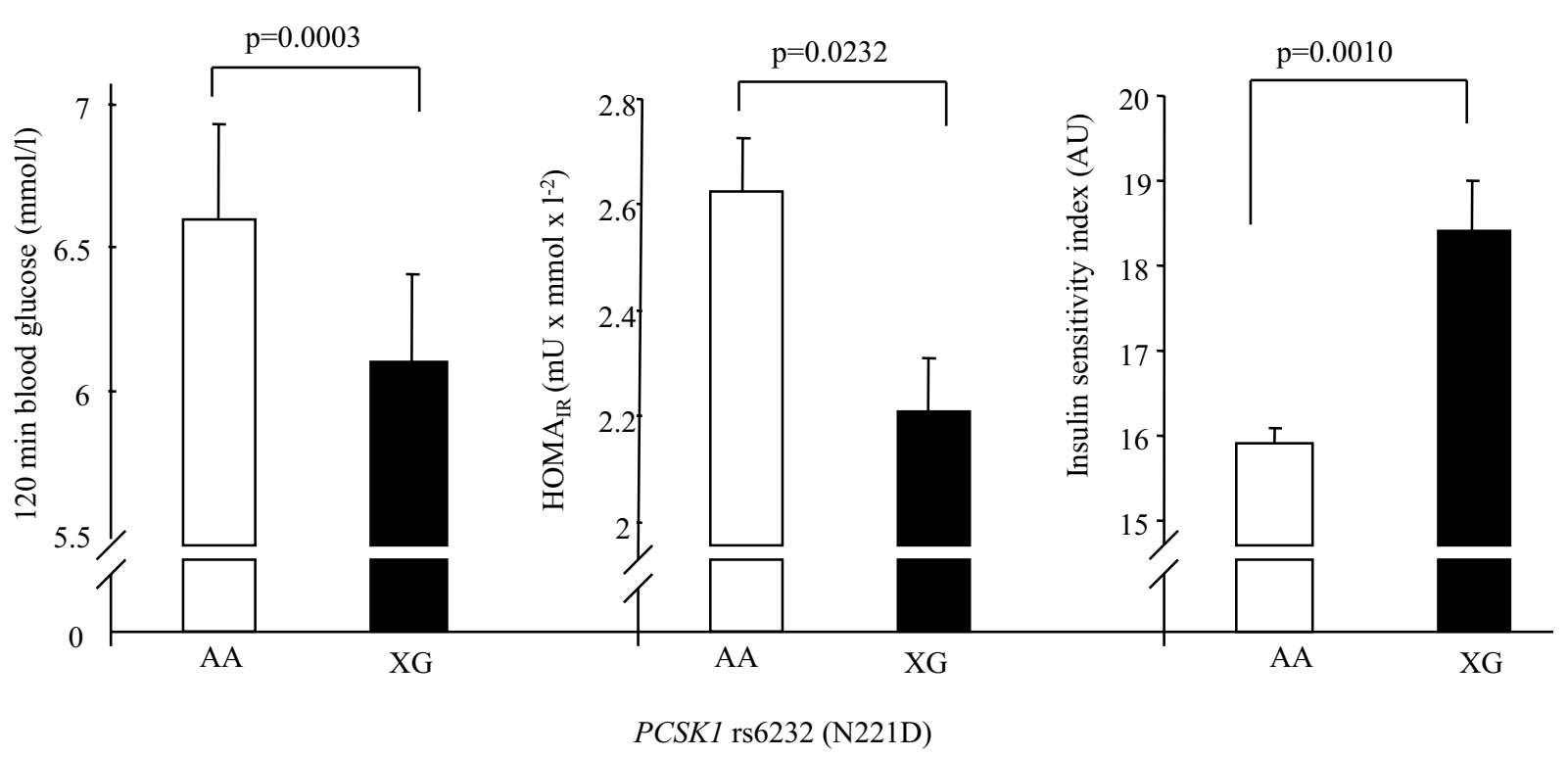

Figure 2 Association of rs6232 (N221D) in PCSK1 gene with insulin sensitivity derived from OGTT, insulin resistance derived from the fasting state $\left(\mathrm{HOMA}_{\mathrm{IR}}\right)$ and 120-min glucose. Data were adjusted for $\mathrm{BMl}$, age and gender (dominant inheritance model).

PCSK1 SNP rs6232 it is the other way round: Those with higher proinsulin concentrations during the OGTT have also increased insulin sensitivity. Similar findings are reported in another publication where insulin resistance was associated with enhanced proinsulin processing in subjects with normal glucose tolerance [25]. Hence, increased proinsulin concentration can not generally be seen as a marker of insulin resistance.

\section{Limitations}

Our study was underpowered to detect the previous reported associations of the PCSK1 variants with obesity. The associations with proinsulin conversion and insulin sensitivity found in this study clearly need replication in other cohorts, in particular, the unexpected association of SNP rs6232 with insulin sensitivity. Furthermore, efforts should also be undertaken to identify prohormone convertase 1 substrates that alter insulin sensitivity and to further characterize these mechanisms. Studies on the molecular level could additionally help to answer the question how PCSK1's SNP rs6235 influences proinsulin levels without changing the enzyme's activity.

\section{Conclusions}

In conclusion, our data suggest that the common genetic variants rs6232 and rs6235 within PCSK1 determine glucose-stimulated proinsulin conversion, but not insulin secretion. In addition, rs6232, encoding the mutation N221D, influences glucose homeostasis and insulin sensitivity independently of BMI and proinsulin concentrations.

\section{Abbreviations}

$\mathrm{HOMA}_{\mathbb{R}}$ : homeostasis model assessment-estimated insulin resistance; MAF: minor allele frequency; $p_{\text {add: }} p$-values from the additive inheritance model; PCSK1: prohormone convertase 1 gene; $p_{\text {dom }}$ : $p$-values from the additive inheritance model; SNP: single nucleotide polymorphism

\section{Competing interests}

The authors declare that they have no competing interests.

\section{Authors' contributions}

$\mathrm{MH}$ and $\mathrm{AH}$ performed the analyses and wrote the manuscript. $\mathrm{MH}, \mathrm{AH}, \mathrm{CT}$, and $\mathrm{CK}$ performed the clinical investigations. FM was responsible for genotyping. NS, HS, and AF controlled the analyses and discussed the paper. NS, H-UH, and AF directed the study. All authors read and approved the final manuscript

\section{Acknowledgements}

We thank all study participants for their cooperation. We gratefully acknowledge the excellent technical assistance of Anna Bury, Alke Guirguis, Melanie Weisser, and Roman Werner. The study was supported in part by a grant from the German Research Foundation (FR 1561/5-1) and a grant from the German Federal Ministry of Education and Research (BMBF) to the German Center for Diabetes Research (DZD e.V.).

\section{Author Details}

'Department of Internal Medicine, Division of Endocrinology, Diabetology, Angiology, Nephrology and Clinical Chemistry, Eberhard Karls University Tübingen, Member of the German Centre for Diabetes Research (DZD), Tübingen, Germany and 2Department of Internal Medicine, Nutritional and Preventive Medicine, Eberhard-Karls-University Tübingen, Tübingen, Germany

Received: 5 February 2010 Accepted: 9 June 2010

Published: 9 June 2010

\section{References}

1. Steiner DF: The proprotein convertases. Curr Opin Chem Biol 1998, 2:31-39.

2. Seidah NG, Mayer G, Zaid A, Rousselet E, Nassoury N, Poirier S, Essalmani R, Prat $A$ : The activation and physiological functions of the proprotein convertases. Int J Biochem Cell Biol 2008, 40:1111-1125. 
3. Khatib AM, Siegfried G, Chretien M, Metrakos P, Seidah NG: Proprotein convertases in tumor progression and malignancy: novel targets in cancer therapy. Am J Pathol 2002, 160:1921-1935.

4. Taylor NA, Van De Ven WJ, Creemers JW: Curbing activation: proprotein convertases in homeostasis and pathology. FASEB J 2003, 17:1215-1227.

5. Seidah NG, Chretien M: Proprotein and prohormone convertases: a family of subtilases generating diverse bioactive polypeptides. Brain Res 1999, 848:45-62

6. Benzinou M, Creemers JW, Choquet $\mathrm{H}$, Lobbens S, Dina C, Durand E, Guerardel A, Boutin P, Jouret B, Heude B, et al.: Common nonsynonymous variants in PCSK1 confer risk of obesity. Nat Genet 2008, 40:943-945.

7. Rouille Y, Duguay SJ, Lund K, Furuta M, Gong Q, Lipkind G, Oliva AA Jr, Chan SJ, Steiner DF: Proteolytic processing mechanisms in the biosynthesis of neuroendocrine peptides: the subtilisin-like proprotein convertases. Front Neuroendocrinol 1995, 16:322-361.

8. Zhu X, Orci L, Carroll R, Norrbom C, Ravazzola M, Steiner DF: Severe block in processing of proinsulin to insulin accompanied by elevation of des64,65 proinsulin intermediates in islets of mice lacking prohormone convertase 1/3. Proc Natl Acad Sci USA 2002, 99:10299-10304

9. Faroogi IS, Volders K, Stanhope R, Heuschkel R, White A, Lank E, Keogh J, O'Rahilly S, Creemers JW: Hyperphagia and early-onset obesity due to a novel homozygous missense mutation in prohormone convertase 1/3. $J$ Clin Endocrinol Metab 2007, 92:3369-3373.

10. O'Rahilly S, Gray H, Humphreys PJ, Krook A, Polonsky KS, White A, Gibson S, Taylor K, Carr C: Brief report: impaired processing of prohormones associated with abnormalities of glucose homeostasis and adrenal function. N Engl J Med 1995, 333:1386-1390.

11. Jackson RS, Creemers JW, Ohagi S, Raffin-Sanson ML, Sanders L, Montague $\mathrm{CT}$, Hutton JC, O'Rahilly S: Obesity and impaired prohormone processing associated with mutations in the human prohormone convertase 1 gene. Nat Genet 1997, 16:303-306.

12. Jackson RS, Creemers JW, Farooqi IS, Raffin-Sanson ML, Varro A, Dockray GJ, Holst JJ, Brubaker PL, Corvol P, Polonsky KS, et al:: Small-intestinal dysfunction accompanies the complex endocrinopathy of human proprotein convertase 1 deficiency. J Clin Invest 2003, 112:1550-1560.

13. Bell CG, Benzinou M, Siddiq A, Lecoeur C, Dina C, Lemainque A, Clement K, Basdevant A, Guy-Grand B, Mein CA, et al:: Genome-wide linkage analysis for severe obesity in french caucasians finds significant susceptibility locus on chromosome 19q. Diabetes 2004, 53:1857-1865.

14. Lafay L, Basdevant A, Charles MA, Vray M, Balkau B, Borys JM, Eschwege E, Romon M: Determinants and nature of dietary underreporting in a free-living population: the Fleurbaix Laventie Ville Sante (FLVS) Study. Int J Obes Relat Metab Disord 1997, 21:567-573.

15. Hager J, Dina C, Francke S, Dubois S, Houari M, Vatin V, Vaillant E, Lorentz $\mathrm{N}$, Basdevant A, Clement K, et al:: A genome-wide scan for human obesity genes reveals a major susceptibility locus on chromosome 10 . Nat Genet 1998, 20:304-308.

16. Chagnon YC, Rice T, Perusse L, Borecki IB, Ho-Kim MA, Lacaille M, Pare C, Bouchard L, Gagnon J, Leon AS, et al:: Genomic scan for genes affecting body composition before and after training in Caucasians from HERITAGE. J Appl Physio/ 2001, 90:1777-1787.

17. Stefan N, Kantartzis K, Machann J, Schick F, Thamer C, Rittig K, Balletshofer B, Machicao F, Fritsche A, Haring HU: Identification and characterization of metabolically benign obesity in humans. Arch Intern Med 2008, 168:1609-1616

18. Stefan N, Machicao F, Staiger H, Machann J, Schick F, Tschritter O, Spieth C, Weigert C, Fritsche A, Stumvoll M, et al: Polymorphisms in the gene encoding adiponectin receptor 1 are associated with insulin resistance and high liver fat. Diabetologia 2005, 48:2282-2291.

19. Stumvoll M, Mitrakou A, Pimenta W, Jenssen T, Yki-Jarvinen H, Van Haeften T, Renn W, Gerich J: Use of the oral glucose tolerance test to assess insulin release and insulin sensitivity. Diabetes Care 2000 23:295-301

20. Matsuda M, DeFronzo RA: Insulin sensitivity indices obtained from oral glucose tolerance testing: comparison with the euglycemic insulin clamp. Diabetes Care 1999, 22:1462-1470.

21. Frayling TM, Timpson NJ, Weedon MN, Zeggini E, Freathy RM, Lindgren $\mathrm{CM}$, Perry JR, Elliott KS, Lango H, Rayner NW, et al: A common variant in the FTO gene is associated with body mass index and predisposes to childhood and adult obesity. Science 2007, 316:889-894

22. Kirchhoff K, Machicao F, Haupt A, Schafer SA, Tschritter O, Staiger H, Stefan $\mathrm{N}$, Haring HU, Fritsche A: Polymorphisms in the TCF7L2, CDKAL1 and
SLC30A8 genes are associated with impaired proinsulin conversion. Diabetologia 2008, 51:597-601.

23. Fujinami A, Ohta K, Obayashi H, Fukui M, Hasegawa G, Nakamura N, Kozai $\mathrm{H}$, Imai S, Ohta M: Serum brain-derived neurotrophic factor in patients with type 2 diabetes mellitus: Relationship to glucose metabolism and biomarkers of insulin resistance. Clin Biochem 2008, 41:812-817.

24. Pfutzner A, Kann PH, Pfutzner AH, Kunt T, Larbig M, Weber MM, Forst T: Intact and total proinsulin: new aspects for diagnosis and treatment of type 2 diabetes mellitus and insulin resistance. Clin Lab 2004, 50:567-573

25. Mykkanen L, Haffner SM, Hales CN, Ronnemaa T, Laakso M: The relation of proinsulin, insulin, and proinsulin-to-insulin ratio to insulin sensitivity and acute insulin response in normoglycemic subjects. Diabetes 1997, 46:1990-1995.

\section{Pre-publication history}

The pre-publication history for this paper can be accessed here: http://www.biomedcentral.com/1471-2350/11/86/prepub

doi: $10.1186 / 1471-2350-11-86$

Cite this article as: Heni et al., Association of obesity risk SNPs in PCSK1 with insulin sensitivity and proinsulin conversion BMC Medical Genetics 2010, $11: 86$

\section{Submit your next manuscript to BioMed Central and take full advantage of:}

- Convenient online submission

- Thorough peer review

- No space constraints or color figure charges

- Immediate publication on acceptance

- Inclusion in PubMed, CAS, Scopus and Google Scholar

- Research which is freely available for redistribution 